\title{
First report of highly pathogenic Echinococcus granulosus genotype G1 in dogs in a European urban environment
}

\author{
Leidi Laurimaa, John Davison, Karmen Süld, Liivi Plumer, Ragne Oja, Epp Moks, Marju Keis, Maris Hindrikson, \\ Liina Kinkar, Teivi Laurimäe, Jaana Abner, Jaanus Remm, Peeter Anijalg and Urmas Saarma*
}

\begin{abstract}
Background: Echinococcus granulosus and E. multilocularis are tapeworm parasites of major medical and veterinary importance, causing cystic and alveolar echinococcosis, respectively. Both diseases are listed among the most severe parasitic diseases in humans, representing 2 of the 17 neglected diseases prioritised by the World Health Organisation. However, little is known about the role of urban animals in transmission of both parasite species.

Findings: A sensitive non-invasive genetic method was used to monitor E. granulosus and E. multilocularis infection among dog faecal samples collected from an urban area in Estonia in 2012-13. Out of 181 dog faecal samples analysed, 2.2\% tested positive for E. granulosus, determined by sequencing as genotype G1. None of the samples tested positive for E. multilocularis.
\end{abstract}

Conclusions: We report contamination of an urban environment with highly pathogenic E. granulosus G1 disseminated by dogs, and a potential risk to human health.

Keywords: Dog, Echinococcosis, Emerging infectious diseases, Molecular diagnostics, Noninvasive genetics, Parasites, Urban dogs, Zoonoses

\section{Findings}

\section{Background}

Tapeworms of the genus Echinococcus are important parasites of mammals, causing life-threatening diseases called echinococcoses. Human echinococcoses are zoonotic diseases that in Europe are caused by two parasite species: E. granulosus, the causative agent of cystic echinococcosis or hydatid disease; and E. multilocularis, which causes alveolar echinococcosis [1]. In Estonia, as well as in the other Baltic States, the number of human cases of echinococcosis is increasing [2]. Human infections are most commonly associated with E. granulosus sensu stricto and, in particular, with its genotype G1 $[3,4]$. While E. granulosus s.s. in Europe mainly uses domestic dogs as definitive and domestic ungulates as intermediate hosts, the typical transmission cycle of $E$. multilocularis is wildlife-based, predominantly involving

\footnotetext{
* Correspondence: urmas.saarma@ut.ee

Department of Zoology, Institute of Ecology and Earth Sciences, University of Tartu, Vanemuise 46, 51014 Tartu, Estonia
}

red foxes (Vulpes vulpes) as definitive and small rodents as intermediate hosts. Humans are considered as accidental intermediate hosts to both species, and they can be infected by ingesting parasite eggs via direct contact with a definitive host or through contact with contaminated water, soil or food. Due to their close contact with humans, dogs present a considerable risk factor in the spread of echinococcoses to humans [5].

Following recent increases in abundance, red foxes have started to occur regularly in European cities, including urban areas in Estonia [6]. Mirroring the range shift of its definitive host, E. multilocularis has also colonised the urban environment. The parasite has been recorded in foxes in a number of European cities $[7,8]$ and recently also in Tartu, Estonia [9], prompting considerable concern for public health. To date the only report of E. granulosus infection in urban areas within the European Union occurred several decades ago when the parasite infection was detected in urban dogs in Rome [10]. However, the problem seems more serious than 
previously thought: in other European countries, including Montenegro and Serbia, the infection rate of urban dogs was found to be very high, up to $65 \%[11,12]$, and a cat with E. granulosus G1 cysts was recently found in Saint-Petersburg, Russian Federation [13].

The aim of this study was to monitor urban dog faecal samples for contamination with E. granulosus and $E$. multilocularis eggs using non-invasive genetics.

\section{Methods}

\section{Non-invasive sample collection}

Dog faecal samples were collected from January to March in 2012 and 2013 from the streets and green areas of Tartu, Estonia. We surveyed 14 transects, each approximately $4 \mathrm{~km}$ long (more than $850 \mathrm{~km}$ in total), incorporating all major districts in the city (Figure 1). Each transect was searched weekly during the study period. We collected 102 dog scat samples that were deep frozen at $-80^{\circ} \mathrm{C}$ for at least one week to avoid the risk of Echinococcus infection [5], since both E. multilocularis $[9,14]$ and E. granulosus [15,16] have recently been found in Estonia and have elsewhere been found to infect dogs [17-19].

\section{Molecular analysis}

Samples were processed and PCR-based molecular analysis was carried out as described in Laurimaa et al. [9]. Essentially, scat samples of approximately $250 \mathrm{mg}$ were placed into tubes, heated for 15 minutes and placed back at $-80^{\circ} \mathrm{C}$. The heating and cooling procedure helps to break the parasite egg shells, enabling efficient DNA extraction. DNA was extracted using the QIAamp DNA
Stool Mini Kit (Qiagen) according to the manufacturer's instructions. Primers $\mathrm{F} 1 / \mathrm{RVu}$ and Dog1f/HW1r were used to amplify short sequences of mitochondrial DNA with total lengths of $76 \mathrm{bp}$ and $56 \mathrm{bp}$ to distinguish between fox and dog, respectively [9].

All samples were further analysed for E. granulosus and E. multilocularis using primer pairs specific to E. multilocularis (EMfor1, EMrev1) and E. granulosus (EGfor1, EGrev1), amplifying 120 bp and 149 bp sequences, respectively [9]. PCR was performed twice for each sample in a total volume of $20 \mu \mathrm{l}$ using the touchdown protocol described in Laurimaa et al. [9]. All positive samples for $E$. granulosus were sequenced with the same primers as used for PCR. PCR product purification and sequencing procedures followed Saarma et al. [20].

\section{Results}

DNA was successfully PCR-amplified from 90 samples out of 102 (success rate 88\%). The PCR-based genetic analysis and sequencing verified that all samples belonged to dogs (data not shown). We also included 91 dog samples previously identified and analysed for E. multilocularis [9], but not for E. granulosus. Thus, in total a further $181 \mathrm{dog}$ samples were analysed to determine infection with $E$. granulosus, and 90 samples were analysed for E. multilocularis. While none of the analysed dog samples were positive for E. multilocularis, we detected E. granulosus in four dog faecal samples (2.2\%; 95\% binomial confidence interval 0.6-5.6\%; Figure 1; Figure 2).

Sequence analysis demonstrated that E. granulosus found in urban dogs in Tartu belonged to genotype G1 (the 'sheep strain') and was $100 \%$ homologous to $E$.

\section{Dogs infected with Echinococcus granulosus in Tartu, Estonia}

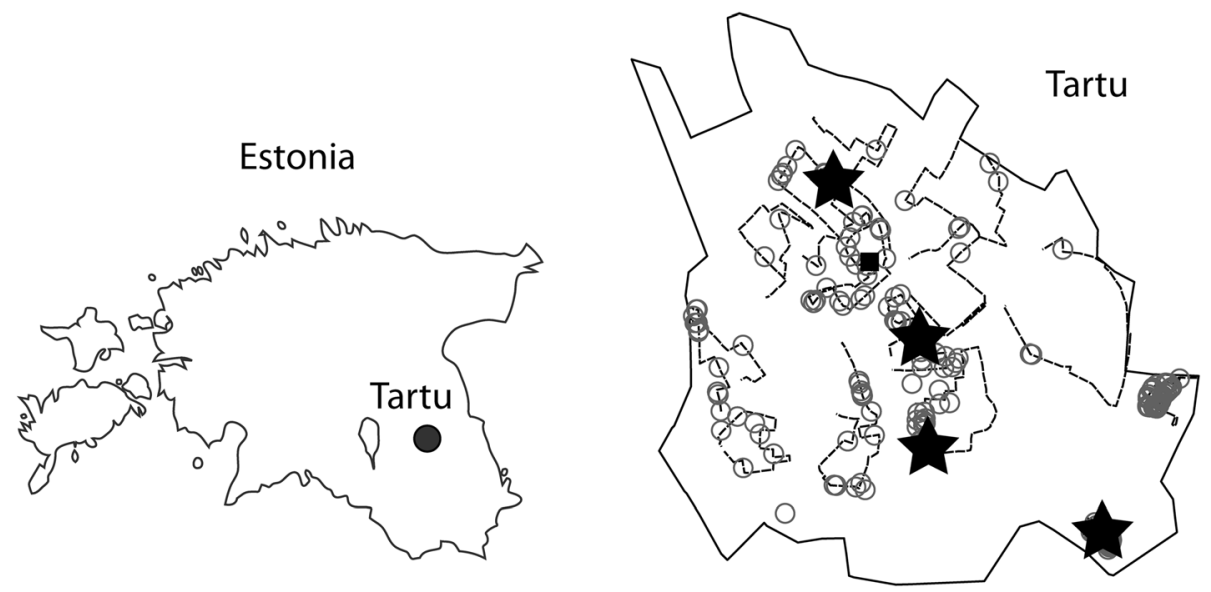

Figure 1 The location of Tartu in Estonia (left), and the dog faeces survey area in Tartu (right). Tartu city boundary is marked with a solid black line; survey transects are shown by dashed lines; and a rectangle marks the city centre of Tartu. Recorded dog faecal samples (181) are shown by open circles, while filled stars (4) indicate $E$. granulosus positive dog faecal samples. 


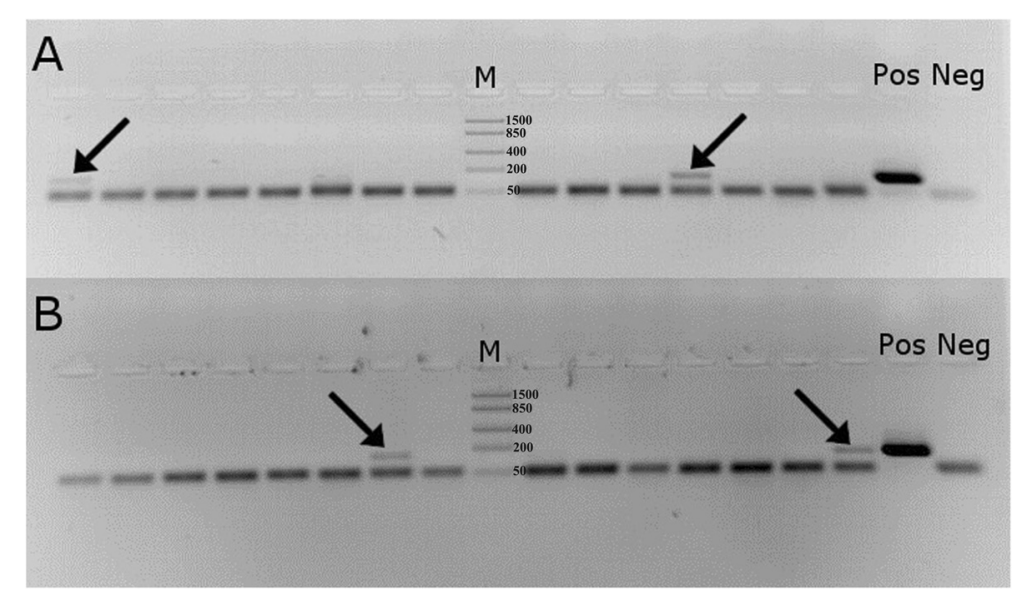

Figure 2 PCR amplification of Echinococcus granulosus mitochondrial small-subunit rDNA fragment from dog faecal samples collected in Tartu (A and B). Arrows point to the four PCR positive samples for E. granulosus (149 bp). Lane M: FastRuler Low Range DNA Ladder (Thermo Scientific; fragment sizes in base-pairs are as follows: 1500, 850, 400, 200 and 50); lane Neg: negative control; lane Pos: positive control.

granulosus genotype 1 sequence AF297617 (pos. 998410133; small-subunit rDNA), whereas in comparison with the other Echinococcus species, the identity was $\leq 95 \%$; Figure 3).

\section{Discussion}

This study provides the first record of E. granulosus genotype G1 in dogs in a European urban environment. Moreover, while $E$. multilocularis has recently been reported in urban areas of the European Union, including Estonia [7-9], this is the first such record of E. granulosus for approximately 20 years. In rural areas of Estonia, both $E$. multilocularis and E. granulosus sensu lato are present: the former has been described in red foxes [14]; the latter in wolf (Canis lupus) and moose (Alces alces) [15,16]. Moks et al. $[15,16]$ demonstrated that the sylvatic cycle of $E$. granulosus in Estonia involves moose (genotypes G8 and G10) as the primary intermediate host, and wolf (G10) as the definitive host. Roe deer (Capreolus capreolus) and wild boar (Sus scrofa) have also been examined for the presence of E. granulosus, and published results have reported no cysts [16]. Furthermore, E. granulosus has recently been

\begin{tabular}{|c|c|c|c|c|c|c|c|c|}
\hline Dog_Tartu_genotype G1 & $\begin{array}{l}10 \\
\ldots \ldots \mid \ldots \ldots \text { | } \\
\text { TGTGTGTAC }\end{array}$ & ${ }_{\text {ATTAATAAGG }}^{20}$ & $\begin{array}{r}30 \\
\ldots \text {. I . . I } \\
\text { GTGTTATTGT }\end{array}$ & $\begin{array}{l}40 \\
\ldots \text { AAGATGATGT }\end{array}$ & $\begin{array}{c}50 \\
\ldots \text { G--ATTTAGG }\end{array}$ & $\begin{array}{r}60 \\
\ldots 1 \ldots \ldots 1 \\
\text { ACTTAATAGT }\end{array}$ & $\left.\ldots 1 \ldots\right|^{70}$ & $\begin{array}{c}\text {. . I . . . } \\
\text { TGAGTTTTT }\end{array}$ \\
\hline AF 297617 genotype G1 & $\ldots \ldots \ldots$ & $\ldots \ldots \ldots$ & $\ldots \ldots \ldots$ & $\ldots \ldots \ldots$ &.$-\ldots \ldots$ & $\ldots \ldots \ldots$ & $\ldots \ldots-\ldots$ & $\ldots \ldots \ldots$ \\
\hline AB786665_genotype G4 & $\ldots \ldots \ldots$ & $\ldots \ldots \ldots$ & $\ldots$. $\ldots$ & .T.GA.A. & $\mathbf{T}--\ldots \ldots$ & $\ldots \ldots \ldots$ & $\ldots$. & $\ldots \ldots \ldots$ \\
\hline AB235846_genotype G5 & $\ldots \ldots \ldots$ & $\ldots \ldots \ldots$ & $\ldots \ldots \ldots$ & $\ldots$ T...A. & $\mathbf{T}--\ldots \ldots$ & $\ldots \ldots \ldots$ & $\ldots \ldots$ т... & A. $\ldots \ldots$ \\
\hline AB235847_genotype G7 & $\ldots \ldots \ldots$ & $\ldots \ldots \ldots$ & $\ldots$. G... & .T. . . & $\mathbf{T}--\ldots \ldots$ & $\ldots \ldots \ldots$ & ...т. & т..... \\
\hline AB235848_genotype G8 & $\ldots \ldots \ldots$ & $\ldots \ldots \ldots$ & $\ldots$. G... & $\ldots$ T.... & $\mathbf{T}--\ldots \ldots$ & $\ldots \ldots \ldots$ & $\ldots \ldots$ т. &. $\mathbf{T} \ldots \ldots$ \\
\hline AB745463_genotype G10 & $\ldots \ldots \ldots$ & $\ldots \ldots \ldots$ & $\ldots$. G... & .T. . . & $\mathbf{T}--\ldots \ldots$ & $\ldots \ldots \ldots$ & $\ldots$ т. & .T. \\
\hline AB732958 E. felidis & $\ldots \ldots \ldots$ & .т.... & $\ldots$. G... & .T...A. &.-- & . & . . А . & $\cdots$ \\
\hline AB208546 E. vogeli & $\ldots \ldots \ldots$ & $\ldots G \ldots$ T & $\ldots$. G..A & ...GA.CA. &.$--\ldots \ldots$ & $\ldots \ldots \ldots$ & $\ldots$. . . & $\ldots$ \\
\hline AB208545_E. oligarthrus & $\cdots \cdots \cdots$ & $\ldots$ T...A & A. $\ldots \ldots$ A & ...G... & TGT $\ldots \ldots$ & $\cdots \cdots \cdots$ & $\ldots \ldots-\ldots$ & $\ldots \ldots \ldots$ \\
\hline Dog_Tartu_genotype G1 & $\begin{array}{c}90 \\
\ldots \text { GATGTGAAGA }\end{array}$ & GA. $\left.\ldots\right|^{100}$ & $\begin{array}{l}0 \quad 110 \\
\ldots \ldots|\ldots|^{1} \\
\text { CAGGTACACA }\end{array}$ & $\ldots \ldots|\ldots|^{120}$ & $\begin{array}{c}0 \\
\ldots \ldots 1 \ldots \ldots \\
\text { CCCTCGGTTG }\end{array}$ & $\begin{array}{l}0 \\
\ldots \ldots 1 \ldots 1 \\
\text { TTATTGAGGT }\end{array}$ & $\begin{array}{c}0 \\
\ldots \ldots|\ldots|^{150} \\
\text { AAGTCGTAAC }\end{array}$ & \\
\hline AF $2 \overline{9} 7617$ genotype G1 & $\cdots \cdots \cdots$ & $\cdots \cdots \cdots$ & $\cdots \cdots \cdots$ & $\cdots \cdots \cdots$ & $\cdots \cdots \cdots$ & $\ldots \ldots \ldots$ & $\ldots \ldots \ldots$ & $\cdots$ \\
\hline AB786665_genotype G4 & $\ldots \ldots \ldots$ & $\ldots \ldots \ldots$ & $\ldots \ldots \ldots$ & $\ldots \ldots \ldots$ & $\ldots \ldots \ldots$ & $\ldots \ldots \ldots$ & $\ldots \ldots \ldots$ & $\cdots$ \\
\hline AB235846_genotype G5 & $\ldots \ldots$ AT & AG $\ldots \ldots$ & $\cdots \cdots \cdots$ & $\cdots \cdots \cdots$ & $\ldots \ldots \mathrm{T}$ & $\cdots \cdots \cdots$ & $\cdots \cdots \cdots$ & $\cdots$ \\
\hline AB235847_genotype G7 & $\ldots \ldots$ AT & $\ldots \ldots \ldots$ & $\ldots \ldots \ldots$ & $\ldots \ldots \ldots$ & $\ldots \ldots \ldots$ & $\ldots \ldots \ldots$ & $\ldots \ldots \ldots$ & $\cdots$ \\
\hline AB235848_genotype G8 & $\ldots \ldots$ AT & A.....C & $\ldots \ldots \ldots$ & $\ldots \ldots \ldots$ & $\ldots \ldots \ldots$ & $\ldots \ldots \ldots$ & $\ldots \ldots \ldots$ & $\cdots$ \\
\hline AB745463_genotype G10 & $\ldots \ldots$ AT & $\ldots \ldots \ldots$ & $\ldots \ldots \ldots$ & $\ldots \ldots \ldots$ & $\ldots \ldots \ldots$ & $\ldots \ldots \ldots$ & $\ldots \ldots \ldots$ & $\cdots$ \\
\hline AB732958 E. felidis & A. . . T TG & T..... & $\ldots \ldots \ldots$ & $\ldots \ldots \ldots$ & $\ldots \ldots \ldots$ & $\ldots \ldots \ldots$ & $\ldots \ldots \ldots$ & $\cdots$ \\
\hline AB208546 E. vogeli & $\ldots \ldots \ldots$ & $\ldots \ldots \ldots$ & $\ldots \ldots \ldots$ & $\ldots \ldots \ldots$ & $\ldots \ldots \ldots$ & $\ldots \ldots \ldots$ & $\cdots \cdots \cdots$ & $\cdots$ \\
\hline AB208545_E. oligarthrus & $\cdots \cdots \mathrm{T}$ & $\cdots \cdots \cdots$ & $\cdots \cdots \cdots$ & $\cdots \cdots \cdots$ & $\cdots \cdots \mathbf{T}$ & A. $\ldots \ldots$ & $\cdots \cdots \cdots$ & $\cdots$ \\
\hline \multicolumn{9}{|c|}{$\begin{array}{l}\text { Figure } 3 \text { Alignment of } \boldsymbol{E} \text {. granulosus mitochondrial small-subunit rDNA sequences. 'Dog_Tartu_genotype } 1 \text { ' is the E. granulosus genotype } \\
\text { G1 sequence obtained in this study, all others are homologous sequences from various E. granulosus genotypes and Echinococcus species from } \\
\text { GenBank. The small-subunit rDNA fragment corresponds to positions } 9984-10133 \text { in AF297617. Note that the E. granulosus sequence obtained in } \\
\text { this study shows 100\% identity with the E. granulosus genotype G1 (AF297617). For other Echinococcus species the identity is lower (s95\%). }\end{array}$} \\
\hline
\end{tabular}


reported in cows and pigs, but not in sheep or other farm animals, as reviewed in Marcinkute et al. [2].

Dogs usually become infected with $E$. granulosus genotype $\mathrm{G} 1$ after eating the discarded offal of wild or domestic ungulates $[17,19]$. Since feeding the viscera of wild and domesticated animals to dogs is commonly practiced, dogs may carry the parasite into urban environments following hunting trips in rural areas. Free-roaming stray dogs that move between rural and urban areas can also be a source of contamination. Since the genotype (G1) we detected differs from those recorded from wild mammals in Estonia (G8 and G10), an origin in the sylvatic cycle seems unlikely. The genotype G1 is most probably transmitted via the domestic cycle, and further sampling of production animals is necessary to determine the transmission path of E. granulosus G1 in more detail.

We expected that dogs included in this study might also harbour E. multilocularis infection, since about 30\% of foxes in rural areas [14] and 7.1\% of the analysed fox scats from the same urban area (Tartu) were found to be infected [9]. Moreover, 1.6\% of raccoon dogs (Nyctereutes procyonoides) harboured the adult tapeworms in their small intestines (Laurimaa et al., unpublished). Given the relatively high densities of foxes and raccoon dogs in Estonia, both species seem to represent important definitive host species for E. multilocularis (and for other zoonotic pathogens in the country) [21]. However, none of the dogs analysed in Tartu were identified as E. multilocularis-positive, though such cases have been reported in Slovakia, where hunting rodents and feeding on raw viscera were found to be the main risk factors of $E$. multilocularis infection in dogs [17].

Decisions about the treatment and control of echinococcosis should rely on the accurate identification of Echinococcus species and genotypes. Morphological methods often fall short in such identifications due to specific limitations. Recent advances in the development of molecular methods have laid a solid basis for accurate detection of Echinococcus species and genotypes [9,22-26]. Nonetheless, it is highly desirable to have a sensitive and low-cost molecular diagnostic method that also allows Echinococcus parasites and their host species to be detected from degraded samples (e.g. faecal). The molecular diagnostics we used in Laurimaa et al. [9] and in this study is highly sensitive, being able to detect infection of a scat sample with a single Echinococcus egg. It is especially suitable for analyzing faecal samples since it uses relatively short sequences of mitochondrial DNA, allowing species-specific signals to be detected from samples where DNA may be highly degraded. As the method is based on regular PCR, it is also relatively low-cost.

\section{Competing interests}

The authors declare that they have no competing interests.

\section{Authors' contributions}

$L L, J D$, US designed the study; all authors participated in fieldwork; $L L$ and US performed laboratory analyses; LL, JD and US performed data analysis; LL, JD and US drafted the manuscript: All authors have read and approved the final manuscript.

\section{Acknowledgements}

This work was supported by institutional research funding (IUT-2032) from the Estonian Ministry of Education and Research, by grants ESF-8793 and ESF-8525 from the Estonian Research Council, the European Union through the European Regional Development Fund (Centre of Excellence FIBIR), and the Estonian Doctoral School of Ecology and Environmental Sciences.

Received: 23 January 2015 Accepted: 11 March 2015

Published online: 26 March 2015

\section{References}

1. Pawlowski ZS, Eckert J, Vuitton DA, Ammann RW, Kern P, Craig PS, et al. Echinococcosis in humans: clinical aspects, diagnosis and treatment. In: Eckert J, Gemmell MA, Meslin FX, Pawlowski ZS, editors. WHO/oie manual on echinococcosis in humans and animals: a public health problem of global concern. Paris: WHO/OIE; 2001. p. 20-71.

2. Marcinkute A, Šarkunas M, Moks E, Saarma U, Jokelainen P, Bagrade G, et al. Echinococcus infections in the Baltic region. Vet Parasitol. 2015; (in press).

3. Thompson RC. The taxonomy, phylogeny and transmission of Echinococcus. Exp Parasitol. 2008;119:439-46.

4. Alvarez Rojas CA, Romig T, Lightowlers MW. Echinococcus granulosus sensu lato genotypes infecting humans - review of current knowledge. Int J Parasitol. 2014;44:9-18.

5. Eckert J, Gottstein B, Heath D, Liu F-J. Prevention of echinococcosis in humans and safety precautions. In: Eckert J, Gemmell MA, Meslin FX, Pawlowski ZS, editors. WHO/OIE manual on echinococcosis in humans and animals: a public health problem of global concern. Paris: WHO/OIE; 2001. p. 238-47.

6. Plumer L, Davison J, Saarma U. Rapid urbanization of red foxes in Estonia: distribution, behaviour, attacks on domestic animals, and health-risks related to zoonotic diseases. PLoS ONE. 2014;9(12):e115124. doi:10.1371/journal. pone.0115124.

7. Hofer S, Gloor S, Müller U, Mathis A, Hegglin D, Deplazes P. High prevalence of Echinococcus multilocularis in urban red foxes (Vulpes vulpes) and voles (Arvicola terrestris) in the city of Zurich Switzerland. Parasitology. 2000;120:135-42.

8. Deplazes P, Hegglin D, Gloor S, Romig T. Wilderness in the city: the urbanization of Echinococcus multilocularis. Trends Parasitol. 2004;20:77-84.

9. Laurimaa L, Davison J, Plumer L, Süld K, Oja R, Moks E, et al. Noninvasive detection of Echinococcus multilocularis tapeworm in urban area Estonia. Emerg Infect Dis. 2015;21:163-4.

10. Tassi $P$, Widenhorn $O$. Research on intestinal parasitic diseases in dogs of the city of Rome. Parassitologia. 1977;19:43-57.

11. Katic-Radivojevic S, Popovic I. Echinococcosis in Yugoslavia (Montenegro): prevalence of Echinococcus granulosus in stray dogs. In: Menezes da Silva A, Nunes JL, editors. XXXII Archivos Internacionales de la hidatidosis. Lisbon: International Association of Hydatidology; 1997. p. 294.

12. Pavlovic I, Kusilic Z, ErskiBilijic M, Milutinovic M. Role of dogs in environmental contamination with eggs of Echinococcus granulosus. In: Menezes da Silva A, Nunes JL, editors. Archivos Internacionales de la hidatidosis. Lisbon: International Association of Hydatidology; 1997. p. 278.

13. Konyaev SV, Yanagida T, Ivanov MV, Ruppel W, Sako Y, Nakao M, et al. The first report on cystic echinococcosis in a cat caused by Echinococcus granulosus sensu stricto (G1). J Helminthol. 2012:86:391-4.

14. Moks E, Saarma U, Valdmann H. Echinococcus multilocularis in Estonia. Emerg Infect Dis. 2005;11:1973-4.

15. Moks E, Jõgisalu I, Saarma U, Talvik H, Järvis T, Valdmann H. Helminthologic survey of the wolf (Canis lupus) in Estonia, with an emphasis on Echinococcus granulosus. J Wildlife Dis. 2006;42:359-65.

16. Moks E, Jõgisalu I, Valdmann H, Saarma U. First report of Echinococcus granulosus $\mathrm{G} 8$ in Eurasia and a reappraisal of the phylogenetic relationships of "genotypes" G5-G10. Parasitology. 2008;135:647-54.

17. Antolova D, Reiterova K, Miterpakova M, Dinkel A, Dubinsky P. The first finding of Echinococcus multilocularis in dogs in Slovakia: an emerging risk for spreading of infection. Zoonoses Public Health. 2009;56:53-8. 
18. Bružinskaite $R$, Šarkunas $M$, Torgerson PR, Mathis $A$, Deplazes P. Echinococcosis in pigs and intestinal infection with Echinococcus spp. in dogs in southwestern Lithuania. Vet Parasitol. 2009;160:237-41.

19. Deplazes P, van Knapen F, Schweiger A, Overgaauw PAM. Role of pet dogs and cats in the transmission of helminthic zoonoses in Europe, with a focus on echinococcosis and toxocarosis. Vet Parasitol. 2011:182:41-53.

20. Saarma U, Jõgisalu I, Moks E, Varcasia A, Lavikainen A, Oksanen A, et al. A novel phylogeny for the genus Echinococcus, based on nuclear data, challenges relationships based on mitochondrial evidence. Parasitology. 2009;136:317-28.

21. Süld K, Valdmann H, Laurimaa L, Soe E, Davison J, Saarma U. An invasive vector of zoonotic disease sustained by anthropogenic resources: the raccoon dog in Northern Europe. PLoS ONE. 2014;9(5):e96358. doi:10.1371/ journal.pone.0096358.

22. Trachsel D, Deplazes $P$, Mathis A. Identification of taeniid eggs in the faeces from carnivores based on multiplex PCR using targets in mitochondrial DNA. Parasitology. 2007;134:911-20.

23. Dinkel A, Kern S, Brinker A, Oehme R, Vaniscotte A, Giraudoux P, et al. A real-time multiplex-nested PCR system for coprological diagnosis of Echinococcus multilocularis and host species. Parasitol Res. 2011;109:493-8.

24. Boubaker G, Macchiaroli N, Prada L, Cucher MA, Rosenzvit MC, Ziadinov I, et al. A multiplex PCR for the simultaneous detection and genotyping of the Echinococcus granulosus complex. PLoS Neglect Trop Dis. 2013;7(1):e2017. doi:10.1371/journal.pntd.0002017.

25. Jabbar A, Gasser RB. Mutation scanning analysis of genetic variation within and among Echinococcus species: implications and future prospects. Electrophoresis. 2013;34:1852-62.

26. Isaksson M, Hagström A, Armua-Fernandez M, Wahlström H, Agren E, Miller A, et al. A semi-automated magnetic capture probe based DNA extraction and real-time PCR method applied in the Swedish surveillance of Echinococcus multilocularis in red fox (Vulpes vulpes) faecal samples. Parasite Vector. 2014;7:583

\section{Submit your next manuscript to BioMed Central and take full advantage of:}

- Convenient online submission

- Thorough peer review

- No space constraints or color figure charges

- Immediate publication on acceptance

- Inclusion in PubMed, CAS, Scopus and Google Scholar

- Research which is freely available for redistribution 